\title{
Experimental observation of fatigue degradation in a composite wind turbine blade
}

\author{
Chen, Xiao
}

Published in:

Composite Structures

Link to article, DOI:

10.1016/j.compstruct.2019.01.051

Publication date:

2019

Document Version

Peer reviewed version

Link back to DTU Orbit

Citation (APA):

Chen, X. (2019). Experimental observation of fatigue degradation in a composite wind turbine blade. Composite Structures, 212, 547-551. https://doi.org/10.1016/j.compstruct.2019.01.051

\section{General rights}

Copyright and moral rights for the publications made accessible in the public portal are retained by the authors and/or other copyright owners and it is a condition of accessing publications that users recognise and abide by the legal requirements associated with these rights.

- Users may download and print one copy of any publication from the public portal for the purpose of private study or research.

- You may not further distribute the material or use it for any profit-making activity or commercial gain

- You may freely distribute the URL identifying the publication in the public portal

If you believe that this document breaches copyright please contact us providing details, and we will remove access to the work immediately and investigate your claim. 


\section{Accepted Manuscript}

Experimental observation of fatigue degradation in a composite wind turbine

blade

Xiao Chen

PII:

S0263-8223(18)33547-5

DOI: https://doi.org/10.1016/j.compstruct.2019.01.051

Reference: COST 10568

To appear in:

\section{Composite Structures}

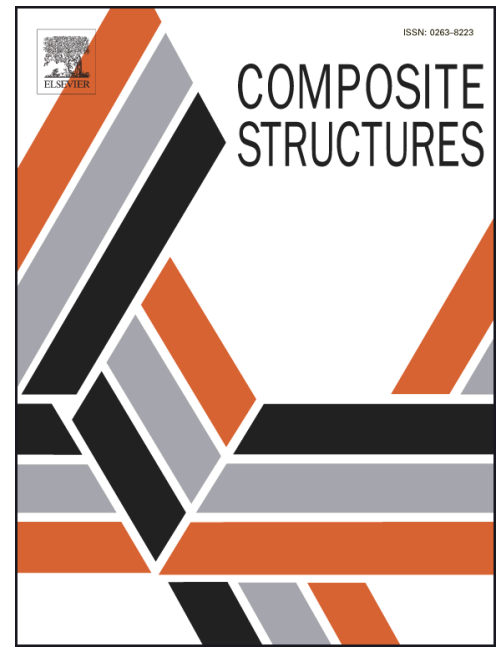

Received Date: $\quad 1$ October 2018

Revised Date: $\quad 9$ December 2018

Accepted Date: $\quad 9$ January 2019

Please cite this article as: Chen, X., Experimental observation of fatigue degradation in a composite wind turbine blade, Composite Structures (2019), doi: https://doi.org/10.1016/j.compstruct.2019.01.051

This is a PDF file of an unedited manuscript that has been accepted for publication. As a service to our customers we are providing this early version of the manuscript. The manuscript will undergo copyediting, typesetting, and review of the resulting proof before it is published in its final form. Please note that during the production process errors may be discovered which could affect the content, and all legal disclaimers that apply to the journal pertain. 


\title{
Short Communication:
}

\section{Experimental observation of fatigue degradation in a composite wind turbine blade}

\author{
Xiao Chen (xiac@dtu.dk) \\ Department of Wind Energy, Technical University of Denmark, Frederiksborgvej 399, 4000 Roskilde, Denmark
}

Abstract: This study reports experimental observation of structural degradation in a composite wind turbine blade subject to fatigue loading. The fatigue test is carried out according to the test standard for the blade certification. The changes of bending stiffnesses, natural frequencies and damping ratios due to fatigue are examined and discussed. The study provides the first of this kind observation on full-scale composite rotor blades in the literature.

Keywords: fatigue degradation, torsional mode, damping, matrix crack, damage, composite blade

\section{Introduction}

Wind turbine blades are expected to sustain a high number of loading cycles typically up to a magnitude of 1,000 million during their targeted service lifetime of 20-25 years. Structural properties of composite blades degrade with the time. Although substantial material tests, such as reported in the Montana State University (MSU) Database Program [1] and the OPTIMAT BLADES project [2], have been carried out to characterize fatigue degradation of composite materials at a coupon level. It is known that the general trend of fatigue degradation in composites has three phases sequentially [3] as illustrated in Figure 1, in which $D$ is often referred to as a damage variable to describe stiffness loss, $E$ and $E_{0}$ are the damaged and undamaged modulus, respectively. The relation $D=1-E / E_{0}$ is usually defined to develop residual stiffness models [4]. The fatigue degradation is rapid at the beginning phase due to the matrix cracking and is gradual and linear in the middle phase due to the coupled matrix cracking and the interfacial deboning, and the degradation comes rapid again near the end of fatigue life due to the fiber breakage as reported in [5-7].

Although it is important to understand the structural behavior of composite blades under fatigue, there is no much experimental study particularly focusing on the fatigue degradation of the composite blades at a full-scale structural level. It is not clear if structural properties of composite blades degrade in a similar manner to what has been observed in the material tests at a coupon level. This study, aims to provide more understanding to this area, presents experimental observation of structural degradation of a $47 \mathrm{~m}$ full-scale composite wind turbine blade subject to fatigue loading up to 2 million cycles. The fatigue test is conducted following the international test standard IEC 61400-23 [8]. The changes of bending stiffness, natural frequencies and damping ratios are measured at different fatigue cycles. A post-fatigue inspection is also conducted to examine structural damages. The degradation trend is discussed in relation to that found in the material tests. 


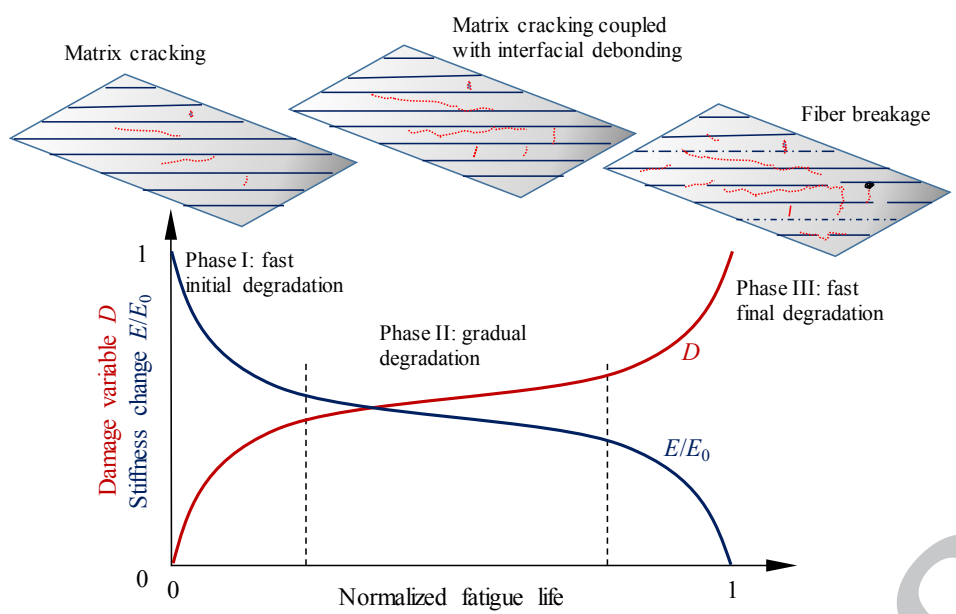

Figure 1. Schematic damage progress and stiffness degradation in composite materials due to fatigue

\section{Experimental setup}

The test specimen is a $47 \mathrm{~m}$ long composite rotor blade for $2 \mathrm{MW}$ wind turbines. The construction and material layup at a typical blade cross section is shown in Figure 2. Unidirectional laminates form a major portion of the spar caps that are primarily responsible for the overall stiffness and the load carrying capacity of the blade. Triaxial laminates form the blade skin at both outside and inside surfaces of the blade. Balsa wood is used in sandwich panels in the blades shells and PVC foam is used in sandwich shear webs.

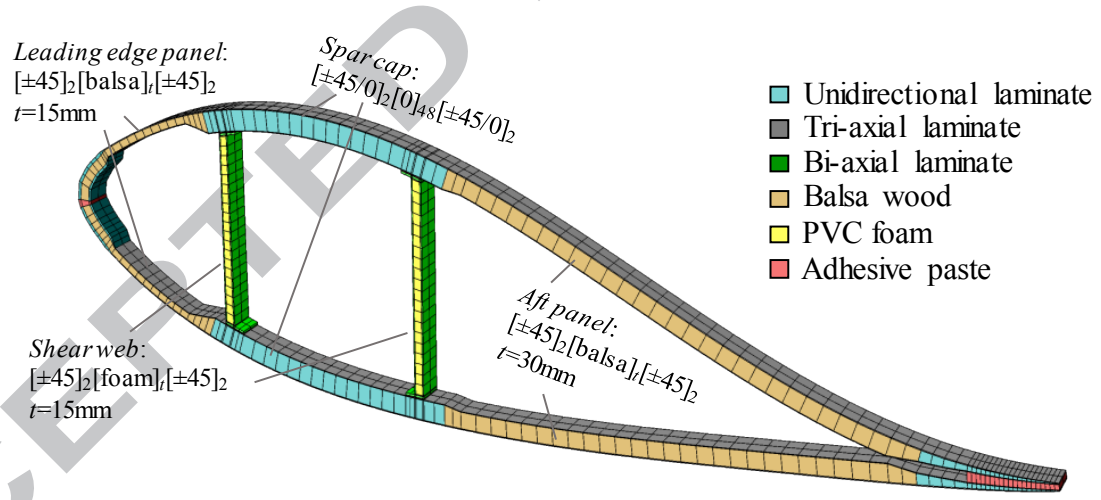

Figure 2. A typical blade cross section at $22 \mathrm{~m}$ from the root

The blade is newly built and it has been tested under static loading according to the test standard [8]. The test data showed that the blade responds to the static loads linearly and no damages was observed after the static test. Subsequently, the blade is subject to fatigue test under flap-wise bending with suction side facing towards the ground. The blade is excited at $39.5 \mathrm{~m}$ from the blade root by an eccentric mass driven be a motor. A tuning mass is also installed at this location to obtain the test bending moment in the blade during the fatigue test. A blade cross section at $22 \mathrm{~m}$ from the blade root is used as a control section in order to match the desired strain level by adjusting tune mass, eccentric mass and of the revolutions per minute (rpm) of the motor. Strain gauges are installed along the blade. The test setup is shown in Figure 3. 


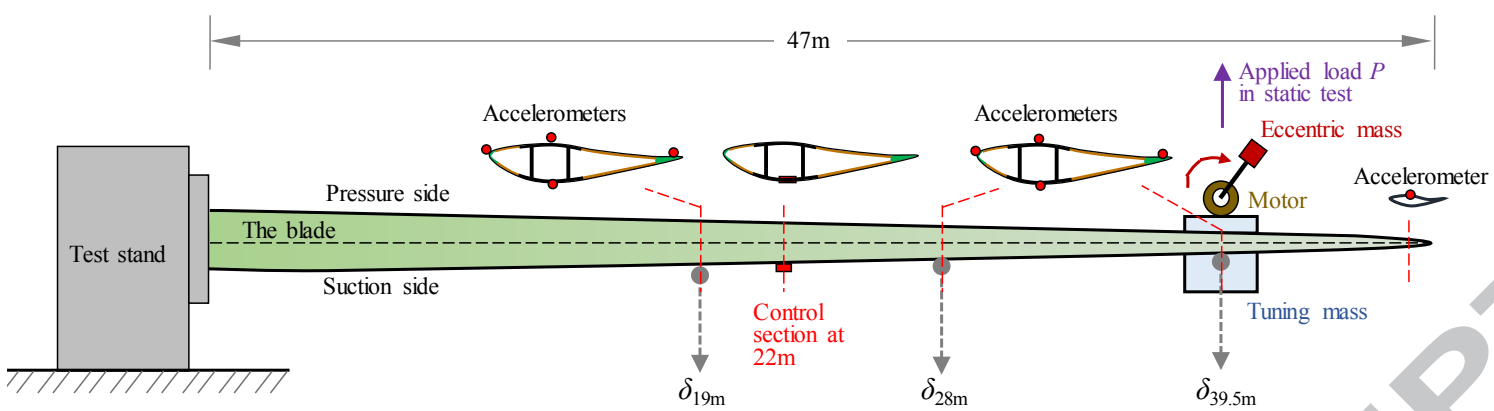

Figure 3. Test setup of the blade

The applied fatigue loads are increased to reduce the number of cycles to 2.0 million cycles. The bending stiffnesses of the blade are measured by stopping the fatigue test at five intervals, i.e., 0, 0.5, 1.0, 1.5 and 2.0 million. A pulling force $P$ is applied at the $39.5 \mathrm{~m}$ section and deflections, $\delta$, at the $19 \mathrm{~m}, 28 \mathrm{~m}$ and $39.5 \mathrm{~m}$ sections are measured suing draw-wire displacement transducers. The bending stiffnesses are calculated as $P / \delta$ at three cross sections of the blade. At each fatigue interval, three measurements are taken for the calculation of the bending stiffnesses.

Natural frequencies and damping ratios of the blade are measured both before and after the blade test when the instrumentations such as the tuning mass, the motor, the eccentric mass and the mounting saddle are removed from the blade. Accelerometers are glued at the leading edge, the trailing edge and the middle width of two spar caps at three blade cross sections which are $19 \mathrm{~m}, 29 \mathrm{~m}$ and $39.5 \mathrm{~m}$ from the blade root, and one more accelerometer is glued close to the blade tip, Figure 3. The pull-and-release of the blade tip is applied to excite the blade to the free vibration. The measurements are taken 5 times.

All tests have been conducted in an accredited test laboratory. The temperatures in the laboratory are recorded before each time when the bending stiffnesses of the blade is measured. They are $17.2^{\circ} \mathrm{C}, 16.5^{\circ} \mathrm{C}, 18.8^{\circ} \mathrm{C}, 17.5^{\circ} \mathrm{C}$ and $15.9^{\circ} \mathrm{C}$ at $0.0,0.5,1.0,1.5$ and 2.0 million cycles, respectively. All sensors used in the tests have been calibrated by an accredited third party. The tests have been witnessed by a certification organization.

\section{Deflection and strain calculation}

The deflection and strain measurements before the fatigue test, or at 0 million cycles, are compared to the finite element analysis (FEA) results when the blade is loaded statically at the $39.5 \mathrm{~m}$ section. The detailed information on the FE model can be found in the previous study [9]. The experimental and numerical results are compared as shown in Figure 4, where the strains are longitudinal strains along the spar caps of the blade. It shows that the blade span from 20 to $32 \mathrm{~m}$ is the most strained region in the spar caps. The distributions of longitudinal stains of the blade are shown in Figure 5. 

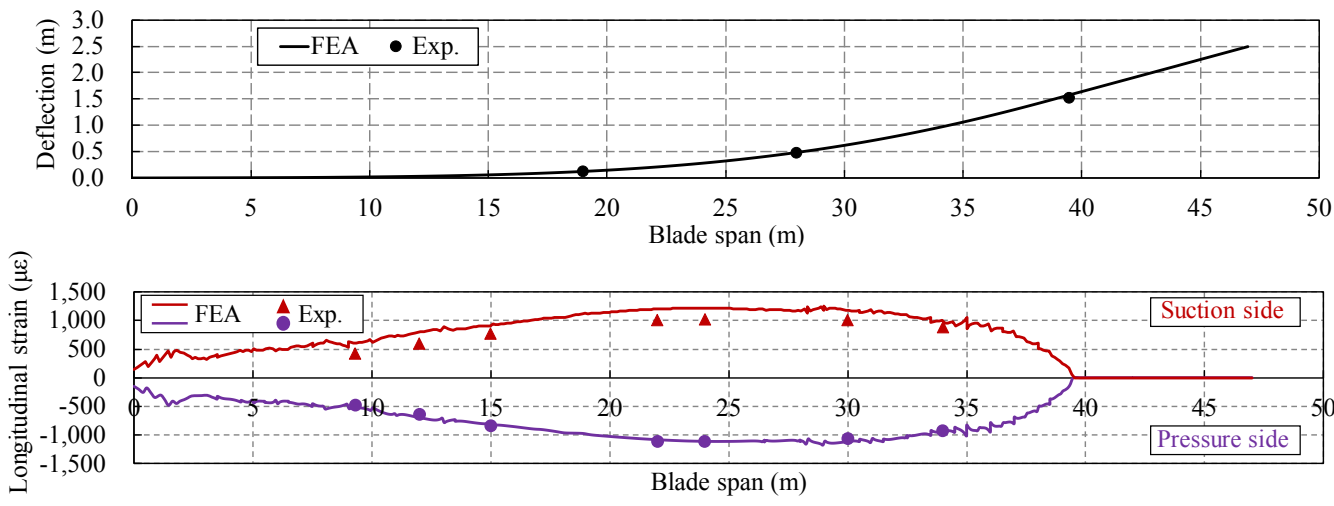

Figure 4. The deflection and longitudinal strain in the spar cap of the blade loaded statically at $39.5 \mathrm{~m}$

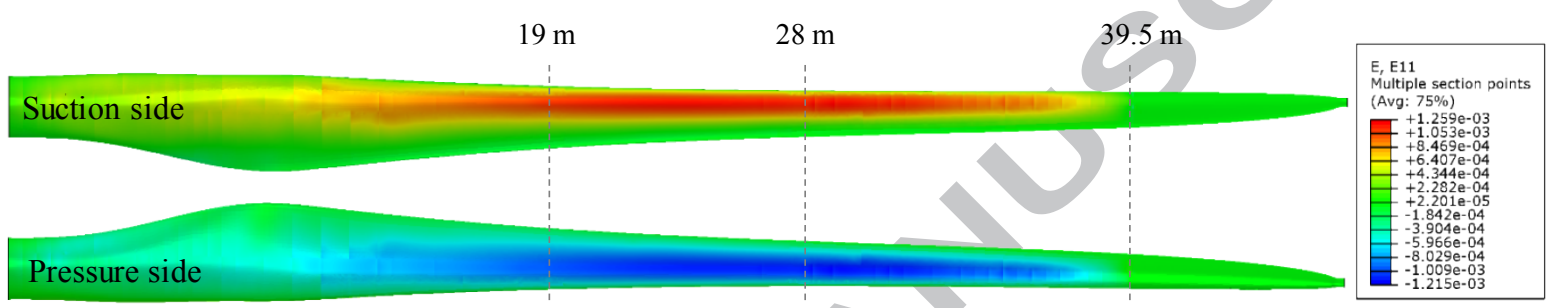

Figure 5. The distribution of longitudinal stains of the blade

\section{Experiment results and discussion}

The bending stiffnesses of the blade at different number of fatigue cycles are shown in Figure 6, where the mean values are shown as columns and the standard deviations are shown as error bars. It can be seen that the bending stiffness of the blade section from 0 to $19 \mathrm{~m}$ does not show obvious degradation during the fatigue test. However, the bending stiffness of the blade from 0 to $28 \mathrm{~m}$ and that from 0 to $39.5 \mathrm{~m}$ showed a clear trend of degradation. The trend is also found to be very similar to that observed in composite materials, which is fast at the early stage and slow at the following stage. It is presumed that the matrix cracking in the off-axis laminates, i.e., the triaxial and biaxial laminates, occurs and progresses rapidly at the beginning of the fatigue. The density of matrix cracks in these off-axis might enter a saturation phase and the unidirectional laminates take the primary loads, leading to a subsequent gradual stiffness degradation. It is noted that the overall stiffness degradation is very small due to the significant amount of the unidirectional laminates compared to the off-axis laminates in the load-carrying spar caps, see Figure 2. The total stiffness decreases are only $2.2 \%$ and $0.7 \%$ for the section from 0 to $28 \mathrm{~m}$ and the section from 0 to $39.5 \mathrm{~m}$, respectively. 

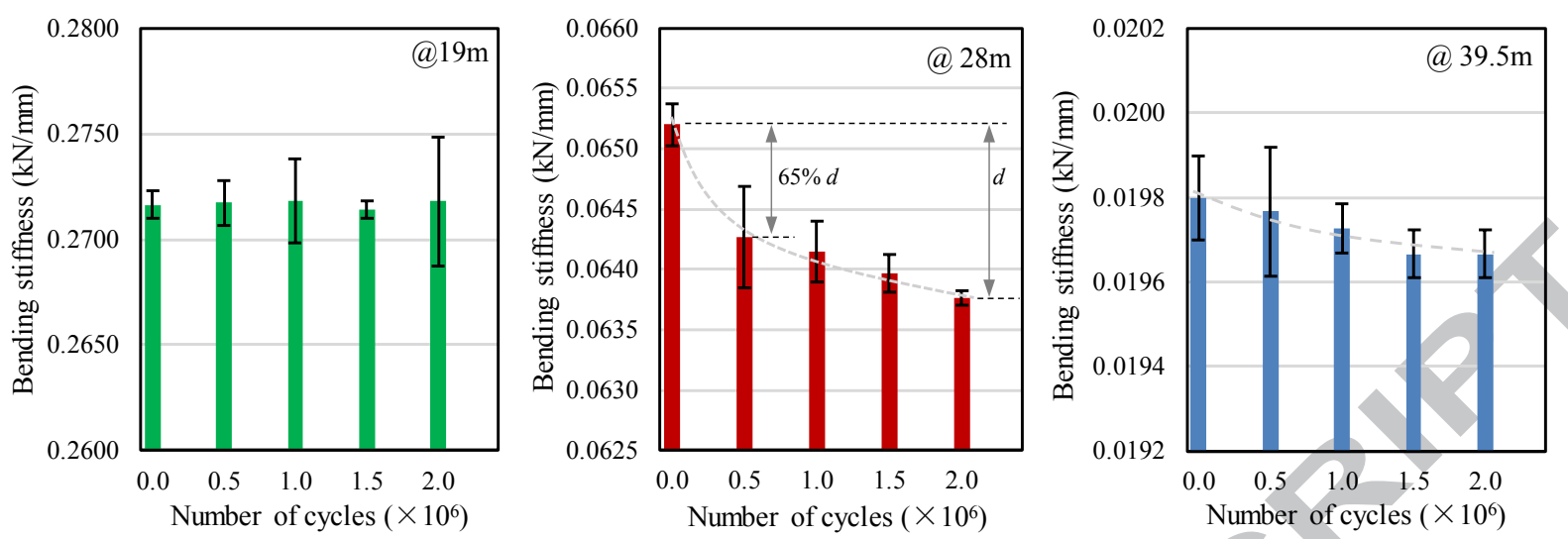

Figure 6. Degradation of bending stiffness of the blade during fatigue test

The changes of natural frequencies after 2.0 million cycles' fatigue is shown in Table 1 . The natural frequencies calculated from the FE model are also listed. Each experimental value is average from five measurements. It can be seen that the changes of natural frequencies due to fatigue are negligible in five different vibrational modes. This observation is reasonable because the blade stiffness has only approximately 1 to $2 \%$ changes while the total mass of the blade is constant. Natural frequencies, which are in principle the square roots of stiffness over mass, will change to an extent that is too small to be noticed. It is also noted that only the first two degradation phases as shown in Figure 1 are observed. The final phase with a rapid stiffness drop does not show in this blade, suggesting the blade might still have a longer fatigue life and possibly a sufficient residual structural strength. This presumption can be partly justified from the post-fatigue structural collapse test [10] in which the blade is able to survive a $140 \%$ standard test load.

Table 1 The changes of natural frequencies after fatigue test

\begin{tabular}{|c|c|c|c|c|c|}
\hline \multirow{2}{*}{ Structural dynamic property } & \multirow{2}{*}{ Modes of vibration } & \multirow{2}{*}{$\begin{array}{c}\text { FEA } \\
-\end{array}$} & \multicolumn{3}{|c|}{ Experiment } \\
\hline & & & Before fatigue & After fatigue & Change $(\%)$ \\
\hline \multirow{5}{*}{ Natural frequency $(\mathrm{Hz})$} & $1^{\text {st }}$ flapwise bending & 0.672 & 0.663 & 0.660 & -0.45 \\
\hline & $1^{\text {st }}$ edgewise bending & 1.238 & 1.227 & 1.220 & -0.57 \\
\hline & $2^{\text {nd }}$ flapwise bending & 2.185 & 2.102 & 2.106 & 0.19 \\
\hline & $2^{\text {nd }}$ edgewise bending & 4.271 & 4.076 & 4.082 & 0.15 \\
\hline & $1^{\text {st }}$ torsion & 9.264 & 8.781 & 8.802 & 0.24 \\
\hline
\end{tabular}

The changes of damping ratios, one the other hand, are found to be quite noticeable, see Figure 7, where the mean values of five measurements are shown as columns and the standard deviations are shown as error bars. The damping ratios increase approximately by $20 \%$ for two flap-wise modes. The changes, if any, of the damping ratios for two edge-wise modes are within the scatter of the measurements. This is regarded to be reasonable due to the fatigue loading in the flap-wise direction. Among all examined vibrational modes, the torsional mode appears to have the most significant increase of the damping ratio in percentage. This observation might be an indication of the considerable damage development in the form of micro cracks in the triaxial laminates around the blade shells, leading to the increase of the energy dissipation when the blade vibrates in the torsional mode. 


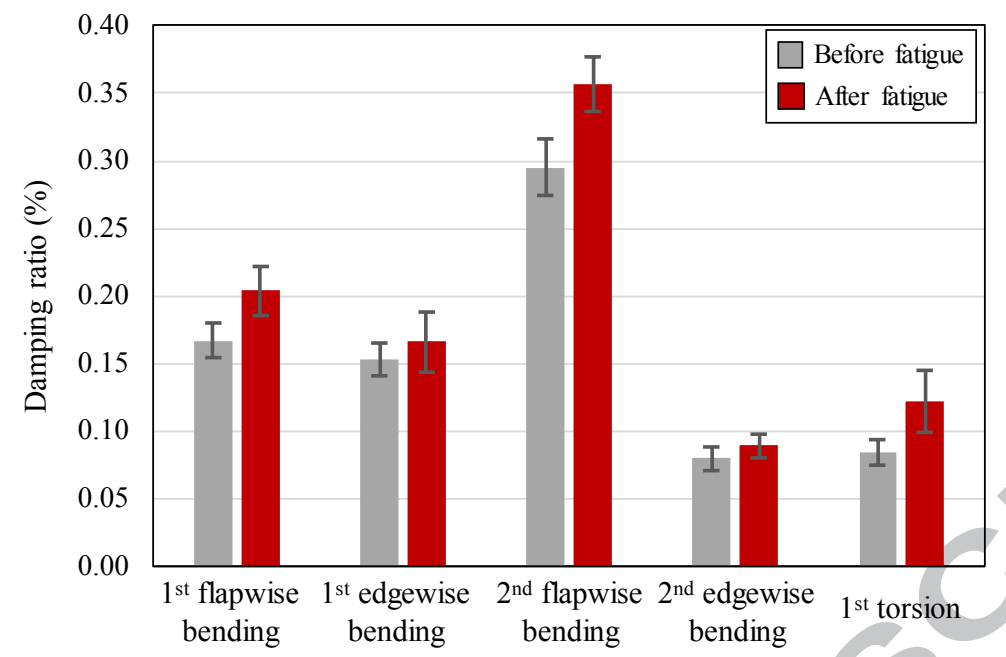

Figure 7. The changes of damping ratios of the blade after fatigue

The post-test inspection is conducted after the fatigue test. A few structural damages are found in the blade. These damages include the whitening of sandwich skins and cracks in core materials and fracture of skin composite materials in the root transition region as shown in Figure 8. These damages are very local and are regarded as too minor to affect the overall structural strength of the blade.
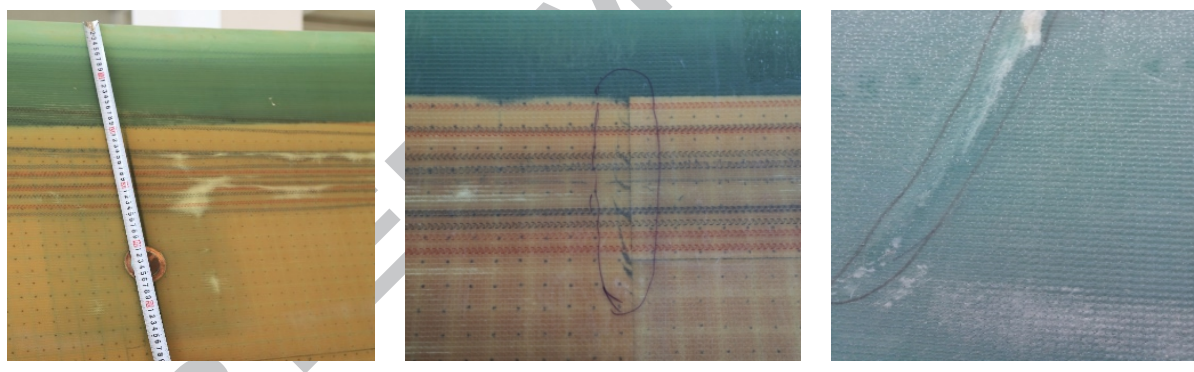

Figure 8 . The observed blade damages after the fatigue test

\section{Conclusions}

The experimental observations presented in this study show that a full-scale blade exhibits a stiffness degradation trend similar to composite materials at the beginning and in the middle phase of the fatigue life. The changes of natural frequencies due to fatigue are negligible $(<1 \%)$. However, the changes of damping ratios are significant in the flap-wise bending modes and the torsional mode. The damping ratios are more practical metrics than the blade stiffness to indicate the overall fatigue damage of composite rotor blades. The significant increase of the damping ratio in torsional mode might be due to the fatigue damage in off-axis fiber composites and sandwich core materials used in the blade shells. The existence of local damages cannot be reflected by the changes of global structural properties. As the fatigue degradation is both specimen and load dependent, the experimental observations found in this study might be only applicable to the blades with similar designs and load conditions.

\section{Acknowledgements:}

The author would like to thank three anonymous reviewers for their valuable comments and kind suggestions to this work. 


\section{References:}

1. Mandell, J.F., Samborsky, D.D., DOE/MSU fatigue of composite materials database. https://energy.sandia.gov/energy/renewable-energy/water-power/technology-development/advancedmaterials/mhk-materials-database/, retrieved on Nov. 1, 2018.

2. Nijssen, R., OptiDat Database, Knowledge Centre WMC, http://www.wmc.eu/optimatblades optidat.php, retrieved on Dec. 5, 2018.

3. Reifsnider, K. L. (1990). Damage and Damage Mechanics, Fatigue of Composite Materials, 4: 11-75.

4. Degrieck, J., Van Paepegem, W., 2001. Fatigue damage modeling of fibre-reindorced composite materials: review, Applied Mechanics Review, ASME, 54(4), 279-300.

5. Nijssen, R.P.L., 2006. Fatigue life prediction and strength degradation of wind turbine rotor blade composites. Ph.D. thesis, Technische Universiteit Delft.

6. Krüger, H, Rolfes, R., 2015. A physically based fatigue damage model for fibre-reinforced plastics under plane loading, International Journal of Fatigue 70, 241-251.

7. Sevenois, R.D.B., Van Paepegem, W., 2015. Fatigue damage modeling techniques for textile composites: review and comparison with unidirectional composite modeling techniques. Applied Mechanics Review, ASME, 67(2), 020802.

8. International Electrotechnical Commission, 2014. IEC Standard 61400-23, Wind Turbines - Part 23: Fullscale Structural Testing of Rotor Blades, Edition 1.0, 2014-04.

9. Chen, X., 2017. Collapse of a 47-meter composite blade under combined bending and torsion in a full-scale static test, AIAA 35th Wind Energy Symposium, 2017, Grapevine, TX, USA.

10. Chen, X., 2017. Experimental investigation on structural collapse of a large composite wind turbine blade under combined bending and torsion. Composite Structures, 160, 435-445. 